\title{
General aviation development prediction research*
}

\author{
Weijun Pan ${ }^{1, a}$, Rundong Wang ${ }^{1, b}$, Lei Yang ${ }^{1, c}$, Chuyang Yang ${ }^{1, d}$, \\ Xingyu Zhuo ${ }^{1, e}$,Jie Luo ${ }^{1, f}$
}

${ }^{1}$ Civil Aviation Flight University of China, Nanchang Rd 4-46 ,Guanghan, Sichuan, 618300,China

a panatc@sina.com, b376176084@qq.com, '347467311@qq.com, d2425917402@qq.com,

e450986574@qq.com, ${ }^{1} 545414447 @ q q . c o m$

Key words: General aviation Improved Grey prediction GM $(1,1)$ model Matlab

Abstract. With the low altitude airspace open in succession in China, the general aviation industry of China began to develop rapidly, so general aviation development prediction has become one of the pressing needs for the future planning of the government and the general aviation enterprise. In view of this, this paper uses the gray system theory to build the improved grey prediction GM $(1,1)$ model, and extracts three important indicators based on general aviation historical statistics of China. Finally, using the Matlab software to map the forecast figure, intuitive reflect the trend of the development of general aviation industry in China. Aimed at providing technical support for the planning and development of chinese general aviation, and it has a certain reference and practicability.

\section{Research Background}

Recently, the State Council and the Central Military Commission jointly issued the "Opinions on deepening the reform of China's low-altitude airspace management", and" Measures of accelerating the development of general aviation" introduced by the Civil Aviation Administration, these policies clearly put forward that to achieve rapid and sustained development of general aviation of China. With a series of positive policies introduced, general aviation is facing unprecedented developing opportunities. The government increased emphasis on general aviation, making the amount of general aviation enterprise, flight hours and margins of business profit are rising steadily, and according to statistics, general aviation flight total average annual growth is more than $10 \%$. General aviation operations spread all over the national economy, social development, scientific research and many other areas. With the scale of industry increased, the application field expanded, the flight species added, so the general aviation flight demand is strong. An urgent need to predict general aviation development is required, thus government departments and companies can formulate corresponding rules and reasonable development plan.

At present, most chinese general aviation researches mainly focused on the analysis of the current situation ,prospect analysis and policy analysis such as qualitative research[1,2].In view of this, this article is based on historical data analysis and research, according to" China general aviation development report" released by China's General Aviation Air Movement Association each year as source of historical data, and extracted three important indicators of the development of general aviation, include general aircraft flight hours, the numbers of general aviation aircraft, and the numbers of business permitted general aviation companies, the index trend of historical

${ }^{*}$ MHRD20140317 project funding 
development is shown in figure 1.

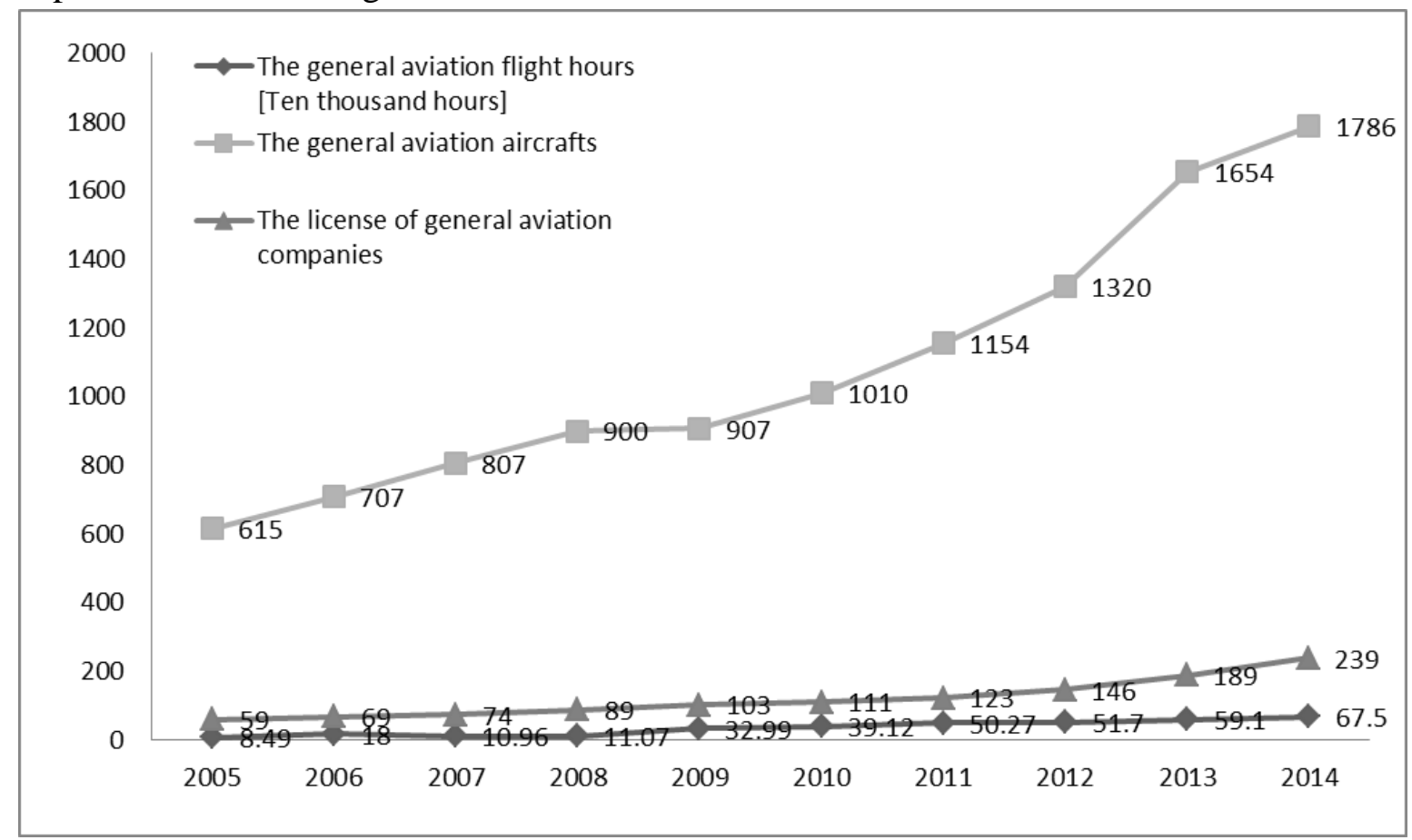

Fig.1 general aviation development trend of every index in our country

To sum up, based on historical data, this article established the improved grey prediction GM (1, 1) model and predicted the China general aviation development data of each index in 2015-2020, by this study can make macro-control departments realized the necessity of the development of general aviation, and provided some references and ideas for general aviation related government departments and enterprises.

\section{Grey System Theory}

The grey system theory is put forward by Chinese scholars, professor Deng Julong in 1982[3], is a new method of poor information uncertainty question. Grey system theory uses "partial information known, the partial information unknown" of "small sample", "poor information" uncertainty system as the research object, mainly through the "part" of the known information generation and development, to extract valuable information, achieve a correct description of system behavior, evolution rule and effective monitoring.

Grey prediction is through the processing of raw data and the establishment of the grey model, discover, master the system development rule, quantitative prediction of the future state of the system scientifically. The choice of model is not invariable, a model through a variety of tests to determine whether it is reasonable, whether effective, only through the inspection of the model can be used to predict. Grey prediction GM $(1,1)$ model is the core content of system theory, through the part of the known data, the system quantitative information of abstract concept, the concept of quantitative model, and the last part to optimize model to predict unknown data.

\section{Model Building}

The improved GM $(1,1)$ model. The construction of traditional grey model forecasting is decreasing the randomness through accumulate the raw data, build the model with much regularly new sequences ,then get the predicted value through data subtraction which from the new building 
model. Coefficient of weight ${ }^{\mu}$ usually be set as 0.5 ,this value is based on experience of experiment, majority of it is subjective, thus we can not prove that precision of prediction is the best when we set $\mu$ as 0.5 .This paper has improved solution for set of $\mu$,uses method called Automatic optimal weighting to select the best $\mu$ in precision of prediction. Thus, it makes the standard deviation of model least.

Step1 : set raw sequence as $x^{(0)}=\left(x^{(0)}(1), x^{(0)}(2), \ldots, x^{(0)}(n)\right)$, get the sequence with once accmulation:

$$
x^{(1)}=\left(x^{(1)}(1), x^{(1)}(2), \ldots, x^{(1)}(n)\right)
$$

In the sequence,

$$
x^{(1)}(k)=\sum_{i=1}^{k} X^{(0)}(i), k=1,2, \ldots, n
$$

Step2: set the sequence as

$$
z^{(1)}(k)=\mu x^{(1)}(k)+(1-\mu) x^{(1)}(k-1), k=2,3, \ldots n .
$$

In the sequence, $z^{(1)}(k)$ is background value, $\mu$ is weight coefficient, $\mu \in[0,1]$.

Step3: build grey differential equation:

$$
x^{(0)}(k)+a z^{(1)}(k)=b, k=2,3, \ldots n .
$$

Transformation it into albinism differential equation: $\frac{d x^{(1)}}{d t}+a x^{(1)}(t)=b$

Step4: assuming $u=[a, b]^{T}, Y=\left[x^{(0)}(2), x^{(0)}(3), \ldots x^{(0)}(n)\right]^{T}, \quad\left(\begin{array}{ll}-z^{(1)}(2) & 1 \\ -z^{(1)}(3) & 1 \\ \vdots & \vdots \\ -z^{(1)}(n) & 1\end{array}\right)$,use the least

square method, get the formula $\mathrm{J}(\mathrm{u})={ }^{(Y-B u)^{T}(Y-B u)}$,obtained the minimum estimated

value u: $\hat{u}=(\hat{a}, \hat{b})^{T}=\left(B^{T} B\right)^{-1} B^{T} Y$.

Then reduced equation

$$
\hat{x}(k+1)=\left(x^{(0)}(1)-\frac{\hat{b}}{\hat{a}}\right) e^{-\hat{a k}}+\frac{\hat{b}}{\hat{a}}, k=0,1, \ldots, n-1, \ldots .
$$


Model Test . Smoothness examination:

$$
\sigma(k)=\frac{x^{(0)}(k)}{x^{(1)}(k-1)}<0.5, k=2,3, \ldots, n \text {. }
$$

Residual examination:

$$
\varepsilon(k)=\frac{x^{(0)}(k)-\hat{x}^{(0)}(k)}{x^{(0)}(k)}, k=1,2, \ldots n
$$

Index regularity examination:

$\delta(k)=\frac{x^{(1)}(k)}{x^{(1)}(k-1)} \in[1,1.5], k=2,3, \ldots, n$.

class-compare verification:

$$
\lambda(k)=\frac{x^{(0)}(k)}{x^{(0)}(k-1)} \in\left[e^{-\frac{2}{n+1}}, e^{\frac{2}{n+1}}\right], k=2,3, \ldots, n
$$

class-compare deviation value verification:

$$
\rho(k)=1-\left(\frac{1-0.5 a}{1+0.5 a}\right) \lambda(k)
$$

\section{Predictive analytics}

According to the established model, and using MATLAB software programming to to get the predict value of general aviation development indicators, as follows.

Table 1 The predict result of general aviation aircraft and comparison error

\begin{tabular}{|c|c|c|c|}
\hline Year & $\begin{array}{c}\text { The general aviation } \\
\text { aircraft }\end{array}$ & Predict value & Relative error \\
\hline 2005 & 615 & 615 & 0 \\
\hline 2006 & 707 & 659 & $6.88 \%$ \\
\hline 2007 & 807 & 745 & $7.67 \%$ \\
\hline 2008 & 900 & 841 & $6.55 \%$ \\
\hline 2009 & 907 & 951 & $4.85 \%$ \\
\hline 2010 & 1010 & 1075 & $6.43 \%$ \\
\hline 2011 & 1154 & 1215 & $5.28 \%$ \\
\hline 2012 & 1320 & 1373 & $4.01 \%$ \\
\hline 2013 & 1654 & 1552 & $6.16 \%$ \\
\hline 2014 & 1786 & 1754 & $1.79 \%$ \\
\hline $\begin{array}{c}\text { Average relative } \\
\text { error }\end{array}$ & \multicolumn{3}{|c}{} \\
\hline
\end{tabular}


Table 2 The Predict value of business permitted general aviation company and comparison error

\begin{tabular}{|c|c|c|c|}
\hline Year & $\begin{array}{c}\text { The business permitted general } \\
\text { aviation company companies }\end{array}$ & Predict value & Relative error \\
\hline 2005 & 59 & 59 & 0 \\
\hline 2006 & 69 & 58 & $1.59 \%$ \\
\hline 2007 & 74 & 69 & $6.75 \%$ \\
\hline 2008 & 89 & 81 & $8.99 \%$ \\
\hline 2009 & 103 & 96 & $6.80 \%$ \\
\hline 2010 & 111 & 113 & $1.80 \%$ \\
\hline 2011 & 123 & 133 & $8.13 \%$ \\
\hline 2012 & 146 & 157 & $7.53 \%$ \\
\hline 2013 & 189 & 186 & $1.59 \%$ \\
\hline 2014 & 239 & 220 & $7.94 \%$ \\
\hline $\begin{array}{c}\text { Average relative } \\
\text { error }\end{array}$ & $6.55 \%$ & \\
\hline
\end{tabular}

Table 3 The predict value of general aviation flight hours and comparison error

\begin{tabular}{|c|c|c|c|}
\hline Year & $\begin{array}{c}\text { general aviation flight hours } \\
\text { [Ten thousand hours] }\end{array}$ & $\begin{array}{c}\text { Predict value } \\
{[\text { Ten thousand hours] }}\end{array}$ & Relative error \\
\hline 2005 & 8.49 & 8.49 & 0 \\
\hline 2006 & 9.19 & 9.47 & $3.02 \%$ \\
\hline 2007 & 10.96 & 10.65 & $2.72 \%$ \\
\hline 2008 & 11.07 & 16.14 & $45.80 \%$ \\
\hline 2009 & 32.99 & 29.12 & $11.73 \%$ \\
\hline 2010 & 39.12 & 35.13 & $10.20 \%$ \\
\hline 2011 & 50.27 & 42.39 & $15.67 \%$ \\
\hline 2012 & 51.7 & 51.15 & $1.06 \%$ \\
\hline 2013 & 59.1 & 61.71 & $4.41 \%$ \\
\hline 2014 & 67.5 & 74.45 & $10.29 \%$ \\
\hline $\begin{array}{l}\text { Average relative } \\
\text { error }\end{array}$ & \multicolumn{3}{|c}{} \\
\hline
\end{tabular}

Compared history value with predict value, every indicator average relative error is $4.96 \%$, $6.55 \%$ and $10.49 \%$ in residual examination , they are less than $20 \%$, so, the precision of model is better.

With this model, predict number of general aviation aircraft, business permitted general aviation company and general aviation flight hours in China from 2015 to 2020, in the following table.

Table 4 The predicted value of the general aviation aircrafts in 2015-2020

\begin{tabular}{|c|c|c|c|c|c|c|}
\hline Year & 2015 & 2016 & 2017 & 2018 & 2019 & 2020 \\
\hline $\begin{array}{c}\text { Predicted } \\
\text { value }\end{array}$ & 1983 & 2242 & 2533 & 2863 & 3236 & 3658 \\
\hline
\end{tabular}


Table 5 the predicted value of the business permitted general aviation companies in 2015-2020

\begin{tabular}{|c|c|c|c|c|c|c|}
\hline Year & 2015 & 2016 & 2017 & 2018 & 2019 & 2020 \\
\hline $\begin{array}{c}\text { Predicted } \\
\text { value }\end{array}$ & 260 & 306 & 361 & 426 & 503 & 593 \\
\hline
\end{tabular}

Table 6 the predicted value of the General aviation flight hours in 2015-2020[Ten thousand hours]

\begin{tabular}{|c|c|c|c|c|c|c|}
\hline Year & 2015 & 2016 & 2017 & 2018 & 2019 & 2020 \\
\hline $\begin{array}{c}\text { Predicted } \\
\text { value }\end{array}$ & 89.83 & 108.38 & 130.76 & 157.77 & 190.35 & 229.66 \\
\hline
\end{tabular}

Programming in MATLAB software to map the forecast figure, " $\Delta$ " presents the original value, $" *$ " presents the prediction value predicted value, as shown in the figure below.

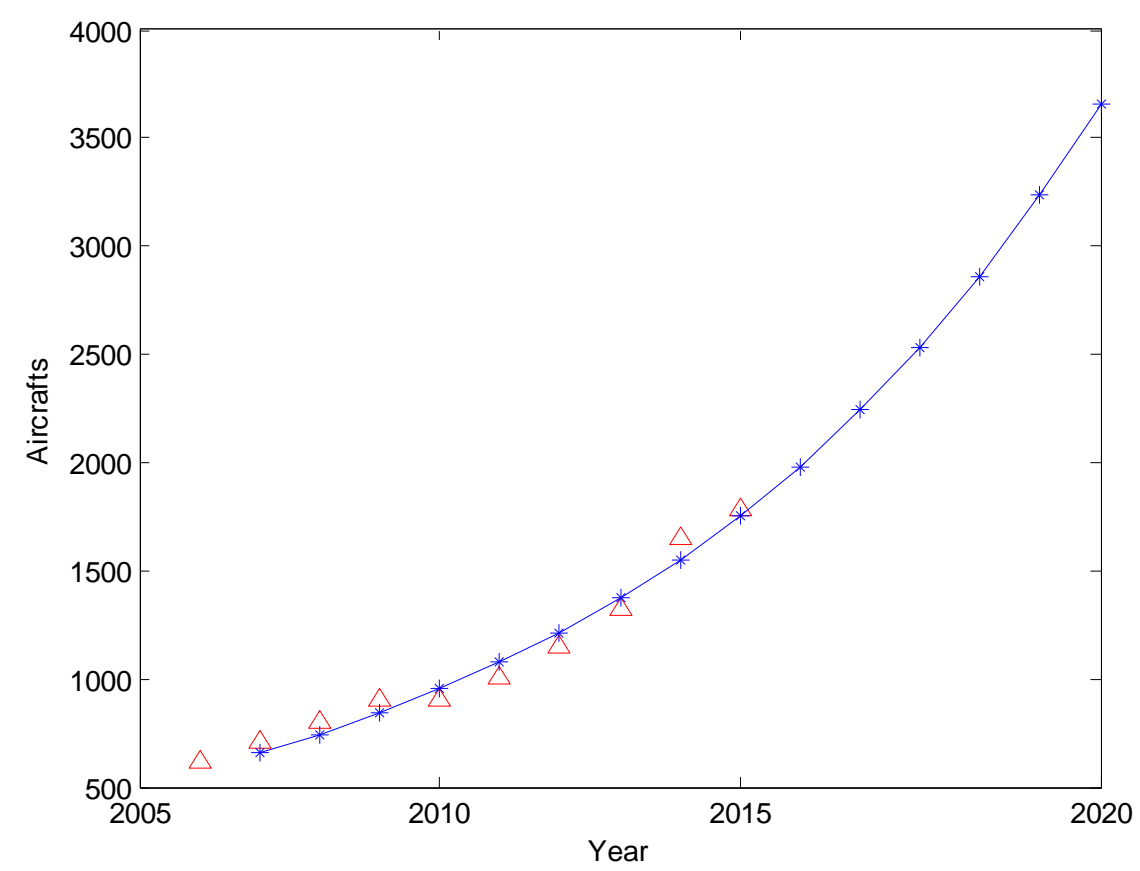

Fig.2 Trend prediction of the general aviation aircraft 


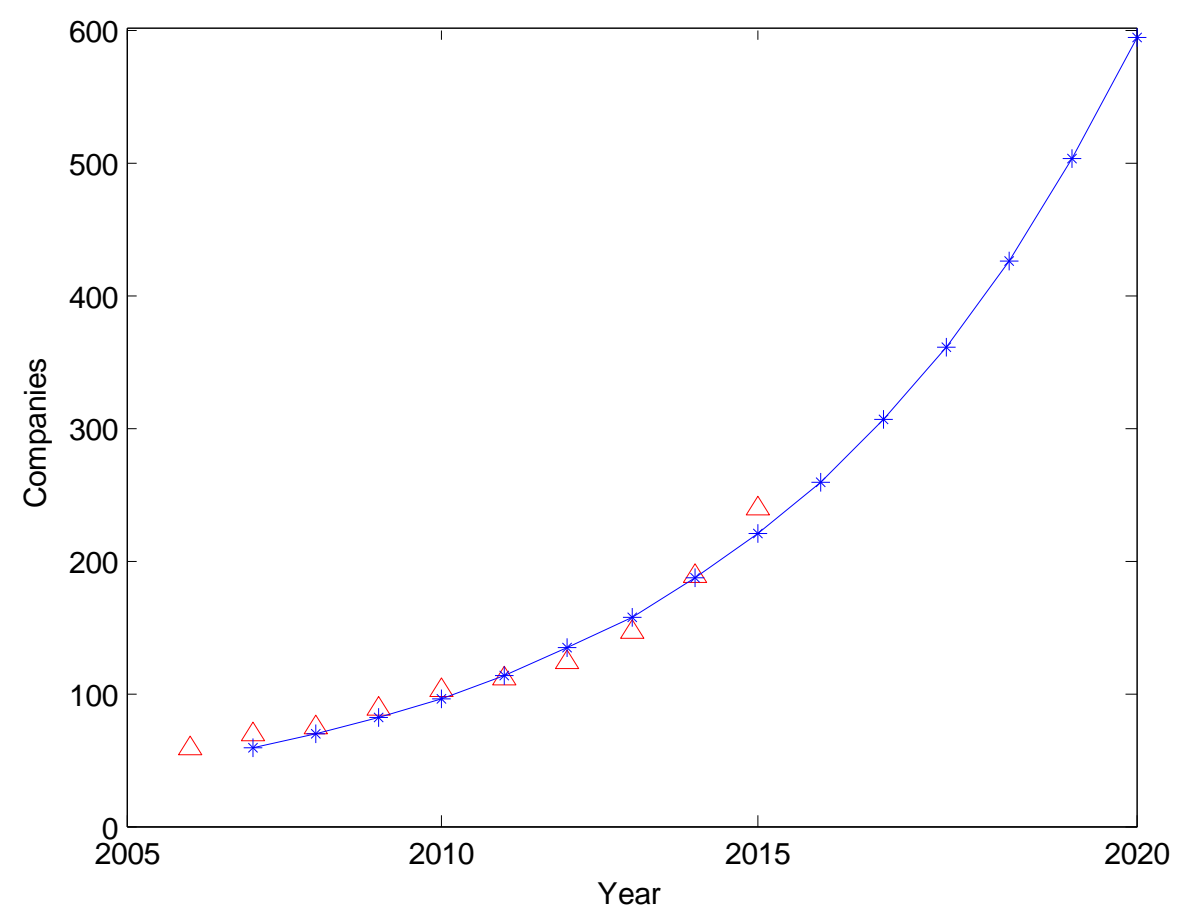

Fig.3 Trend prediction of the business permitted general aviation companies

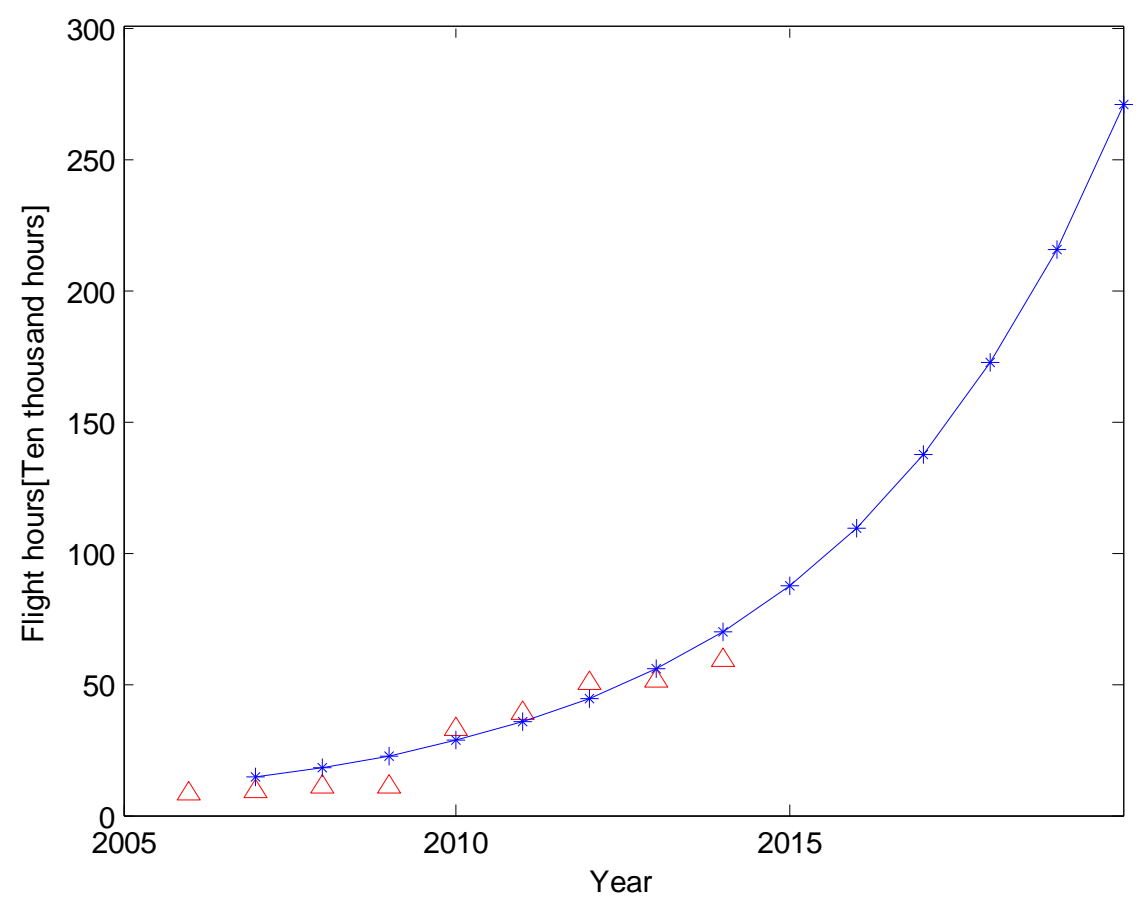

Fig.4 Trend prediction of the general aviation flight hours

Easily to see it from the all of the prediction tendency charts, China is developing our general aviation fastly .In 2020, China has 3,658 general aircraft,593 business permitted general aviation companies,22,966,000 hours general aircraft flight hours, all of them meet the precision demond in residual examination. 


\section{Conclusions}

This paper uses the theory of grey system to predict the numbers of general aviation aircraft, general aviation flight hours and the numbers of business permitted general aviation companies, through the model test, the improved grey prediction GM $(1,1)$ model prediction accuracy is high, which can reflect the actual development of China's general aviation trends. As you can see, according to the trend of the future chinese general aviation in all three indexs will have a lot of growth, this prediction can help the civil aviation system and administration make scientific planning for development of general aviation and provide the decision-making reference.

\section{References}

[1] Hualong Yang, Jinxia Liu, Bin Zheng. Grey prediction GM $(1,1)$ model of the improvement and application [J]. The practice and understanding of mathematics, 2011, 23:39-46.

[2] Cheng Wang, Haitao Zheng, Huiwen Wang, Rong Guan. China's general aviation industry scale prediction research [J]. Productivity research, 2013, 152:152-155

[3] Yong Kang, Jianmin Zhou. General aviation development present situation, trend and countermeasures analysis [J]. Modern navigation, 2012, 12:360-367.

[4] Ao Li. China's general aviation industry development and research [D]. China civil aviation flight institute, 2014.

[5] Qiming Gao. China's general aviation industry development overview in 2014 [J]. Journal of xi 'an aviation academy, 2015, 11:15-18. 